\title{
Contributions of the Ventral Striatum to Conscious Perception: An Intracranial EEG Study of the Attentional Blink
}

\author{
ĐHeleen A. Slagter, ${ }^{1,2}$ @Ali Mazaheri, ${ }^{3}$ @Leon C. Reteig, ${ }^{1}$ Ruud Smolders, ${ }^{4}{ }^{-}$Martijn Figee, ${ }^{4}$ Mariska Mantione, ${ }^{4}$ \\ P. Richard Schuurman, ${ }^{5}$ and ${ }^{-D a m i a a n}$ Denys ${ }^{4,6}$ \\ 1Department of Psychology and ${ }^{2}$ Amsterdam Brain and Cognition, University of Amsterdam, 1018 WS Amsterdam, The Netherlands, ${ }^{3 S}$ chool of \\ Psychology, University of Birmingham, B15 2TT Birmingham, United Kingdom, ${ }^{4}$ Department of Psychiatry, Academic Medical Center, 1105 AZ \\ Amsterdam, The Netherlands, ${ }^{5}$ Department of Neurosurgery, Academic Medical Center, 1105 AZ Amsterdam, The Netherlands, and ${ }^{6}$ The Netherlands \\ Institute for Neuroscience, Royal Netherlands Academy of Arts and Science, 1105 BA Amsterdam, The Netherlands
}

The brain is limited in its capacity to consciously process information, necessitating gating of information. While conscious perception is robustly associated with sustained, recurrent interactions between widespread cortical regions, subcortical regions, including the striatum, influence cortical activity. Here, we examined whether the ventral striatum, given its ability to modulate cortical information flow, contributes to conscious perception. Using intracranial EEG, we recorded ventral striatum activity while 7 patients performed an attentional blink task in which they had to detect two targets (T1 and T2) in a stream of distractors. Typically, when T2 follows T1 within $100-500 \mathrm{~ms}$, it is often not perceived (i.e., the attentional blink). We found that conscious T2 perception was influenced and signaled by ventral striatal activity. Specifically, the failure to perceive T2 was foreshadowed by a T1-induced increase in $\alpha$ and low $\beta$ oscillatory activity as early as $80 \mathrm{~ms}$ after T1, indicating that the attentional blink to T2 may be due to very early T1-driven attentional capture. Moreover, only consciously perceived targets were associated with an increase in $\theta$ activity between 200 and 400 ms. These unique findings shed new light on the mechanisms that give rise to the attentional blink by revealing that conscious target perception may be determined by T1 processing at a much earlier processing stage than traditionally believed. More generally, they indicate that ventral striatum activity may contribute to conscious perception, presumably by gating cortical information flow.

Key words: attentional blink; consciousness; intracranial EEG; oscillations; perception; striatum

Significance Statement

What determines whether we become aware of a piece of information or not? Conscious access has been robustly associated with activity within a distributed network of cortical regions. Using intracranial electrophysiological recordings during an attentional blink task, we tested the idea that the ventral striatum, because of its ability to modulate cortical information flow, may contribute to conscious perception. We find that conscious perception is influenced and signaled by ventral striatal activity. Short-latency $(80-140 \mathrm{~ms})$ striatal responses to a first target determined conscious perception of a second target. Moreover, conscious perception of the second target was signaled by longer-latency $(200-400 \mathrm{~ms})$ striatal activity. These results suggest that the ventral striatum may be part of a subcortical network that influences conscious experience.

\section{Introduction}

A fundamental question in the study of conscious perception relates to the neural basis of conscious access: what brain mech-

Received July 11, 2016; revised Nov. 4, 2016; accepted Nov. 11, 2016.

Author contributions: H.A.S. designed research; R.S., M.F., M.M., P.R.S., and D.D. performed research; H.A.S., A.M., and L.C.R. analyzed data; H.A.S., A.M., L.C.R., and D.D. wrote the paper.

This study was supported by the research program "The healthy brain" funded by the Netherlands Initiative Brain and Cognition, a part of the Organization for Scientific Research (NW0), under Grant 056-14-012 to D.D. and a NWO VIDI Grant to H.A.S. This work was also supported by Medtronic Inc. (unrestricted investigator-initiated research grant), which provided the DBS devices used. We thank Carlos Valencia-Alfonso for help with data collection; Ruud van den Brink for help in programming the task and data preprocessing; and Simon van Gaal for helpful comments on an earlier version of this manuscript. anisms determine whether a stimulus becomes available for explicit report? Research shows that only consciously perceived stimuli are associated with sustained, synchronized activity
The authors have the following interests: P.R.S. is an independent consultant for Medtronic Inc. on educational matters and received travel grants from the company. D.D. has received occasional fees from Medtronic for educational purposes and has served as a consultant for Lundbeck. The DBS intervention was supported by an unrestricted investigator-initiated research grant by Medtronic Inc. There are no patents, products in development or marketed products to declare.

Correspondence should be addressed to Dr. Heleen A. Slagter, Department of Psychology, University of Amsterdam, 1018 WS Amsterdam, The Netherlands. E-mail: h.a.slagter@uva.nl.

DOI:10.1523/JNEUROSCI.2282-16.2016

Copyright $\odot 2017$ the authors $\quad 0270-6474 / 17 / 371081-09 \$ 15.00 / 0$ 
within a distributed network of cortical regions (Rees et al., 2002; Haynes, 2009; Dehaene and Changeux, 2011; Lau and Rosenthal, 2011; Aru et al., 2012; van Gaal and Lamme, 2012). Based on this work, influential theories propose that conscious access stems from a cognitive architecture with an evolved function: the flexible sharing of information throughout the cortex (Baars, 1993; Dehaene and Naccache, 2001). Yet, the cortex operates in close interaction with subcortical regions, specifically the thalamus and the basal ganglia. The thalamus has rich and widespread reciprocal connections to the cortex and thus can synchronize activity across distant cortical regions. Several theories propose that this vast thalamocortical architecture may shape the boundary conditions for both the level of wakefulness (Vijayan and Kopell, 2012; MacDonald et al., 2015) as well conscious perception to occur (Newman and Baars, 1993; Crick, 1995; Tononi and Edelman,

1998; Baars, 2005; Dehaene and Changeux, 2005). Notably, thalamocortical interactions are modulated by the basal ganglia, which tonically inhibit the thalamus and thereby cortical activation. This raises the possibility that the basal ganglia may also contribute to conscious perception, through their influence on activity within the network of frontoparietal regions that gives rise to conscious experience.

The basal ganglia are connected to many frontal regions in parallel loops through the thalamus, and hence capable of modulating a wide range of associated processes. Loops connecting the basal ganglia to motor cortex have long been implicated in action selection. Notably, converging evidence indicates that these parallel loops connecting the basal ganglia and frontal cortex may serve a more generic "selection" function and may resolve conflicts not only in the motor domain, but also among cognitive resources (Redgrave et al., 1999a). Evidence from animal studies suggests that the striatum can act as an early gating system that enables the prioritization of salient stimuli by triggering frontal systems to orient attention (Redgrave and Gurney, 2006; Overton et al., 2014). Moreover, the striatum receives longer-latency input from the hippocampus, which may provide longer-duration, context-dependent gating of prefrontal activity (Newman and Grace, 1999). By gating cortical information flow, the striatum could hence be part of a subcortical network that provides a "gateway" to conscious experience, for example, by biasing attention (van Schouwenburg et al., 2015), and guide which information is selected for global broadcasting and conscious access.

Although the striatum is perfectly situated to influence conscious information processing, little is currently known about its exact contribution to conscious perception. This gap in knowledge is related to our inability to record subcortical activity with high temporal precision in healthy humans and difficulties in studying consciousness in animals. Human neuroimaging studies have provided some support for a role for the striatum and its irrigation by dopamine in conscious perception (Slagter et al., 2010, 2012; Van Opstal et al., 2014; Bisenius et al., 2015). For example, a recent PET study (Slagter et al., 2012) revealed an association between striatal dopamine D2 receptor binding and the attentional blink $(\mathrm{AB})$ : a deficit in consciously perceiving the second target of two targets (T1 and T2) whenever it follows T1 within $100-500 \mathrm{~ms}$ in a rapid stream of distractors. Yet, these neuroimaging methods lack temporal precision and provide indirect measures of neural activity, leaving the specific contribution of the striatum to conscious perception unclear.

To shed light on the potential role of the striatum in conscious perception, we used the unique opportunity to directly record electrophysiological activity from the ventral striatum in patients while they performed an AB task (Raymond et al., 1992). This task has two unique features. First, it has proven useful for studying the neural correlates of conscious perception by comparing the neural processing of T2 between T2-seen versus T2-unseen trials. Second, it allows investigation of the conditions that are necessary for a stimulus to reach awareness by revealing how neural processing of $\mathrm{T} 1$ affects the ability to consciously perceive T2 (Dux and Marois, 2009; Martens and Wyble, 2010). By linking conscious perception to real-time basal ganglia measurements, we aimed to elucidate the role of the ventral striatum in conscious perception.

\section{Materials and Methods}

Participants. Eight therapy-resistant patients eligible for deep brain stimulation (DBS) participated in the study. One patient had difficulty seeing any target, and the experiment had to be aborted prematurely. Of the 7 remaining patients (mean age: 39.5 years; age range: $22-63$ years), 6 were female. Five patients had a diagnosis of obsessive-compulsive disorder, one patient had a diagnosis of major depressive disorder, and another patient had a drug addiction. They participated in the experiment $1 \mathrm{~d}$ (1 patient) or $3 \mathrm{~d}$ (6 patients) after undergoing DBS lead placement surgery and before DBS stimulator implantation. All the patients underwent careful screening before being included for DBS as described by Denys et al. (2010). Patients were implanted following standard procedures with a four contact electrode (model 3387 with contact points $1.5 \mathrm{~mm}$ long and separated from adjacent contacts by $1.5 \mathrm{~mm}$; Medtronic) in each hemisphere. The surgical technique has been described previously (Denys et al., 2010; van den Munckhof et al., 2013). The electrodes were implanted following the anterior limb of the internal capsule (ALIC), with the deepest contact targeted at the core of the nucleus accumbens and the three upper contacts in the ventral ALIC (Fig. 1). DBS leads were externalized at the back of the head based on individual anatomy to facilitate the 
recordings. Correct stereotactic position of the DBS leads was verified with postoperative stereotactic CT. During the subsequent recordings, patients received normal medical treatment in addition to antibiotics and analgesics when requested or deemed medically necessary. However, to reduce the risk of brain hemorrhage, any administration of selective serotonin response inhibitors was suspended. This study was approved by the Institutional Review Board of the Academic Medical Center of the University of Amsterdam.

Task and stimuli. Stimulus presentation was performed using Presentation (version 14.5; Neurobehavioural Systems) and a laptop (Hewlett Packard 6730b) with a 15.4 inch display at a resolution of $1024 \times 768$ pixels (refresh rate of $60 \mathrm{~Hz}$ ). The distance from the screen to the participants was kept at $\sim 60 \mathrm{~cm}$. Participants performed a standard AB task in which they had to identify two digits (T1 and T2) presented in a rapid stream of distractors (letters and symbols) (Fig. 1a). T2 followed T1 either in the time window of the $\mathrm{AB}$, after $200 \mathrm{~ms}$ (short-interval trial), or outside the time window of the $\mathrm{AB}$, after $800 \mathrm{~ms}$ (long-interval trial). Each trial started with a fixation-plus sign $(+; 1500 \mathrm{~ms})$, after which the stimulus stream began, consisting of 22 stimuli. Stimuli were presented on a gray background (red, green, blue [RGB]: 50, 50, 50) at the center of the screen ( 28 point Arial; 0.94 degrees visual angle) for $50 \mathrm{~ms}$, followed by a $50 \mathrm{~ms}$ blank. T1 was either green (RGB: $30,120,55)$ or red (RGB: $140,80,125)$. T2 and the distractors were always blue (RGB: 90, 90, 190). Stimulus colors were matched in luminance. T1 had a different color to make the T2 task more difficult. Digits were drawn randomly (without replacement) from the set $2-9$. Distractors were randomly drawn (without replacement) from the following set of 30 letters and symbols: $\mathrm{W}, \mathrm{E}$, R, T, Y, U, P, A, D, F, G, H, J, K, L, Z, X, C, V, B, N, M, @, \#, \$, \%, \}, \&, <, and $=. \mathrm{T} 1$ position was varied randomly between 7 and 10 . The temporal distance between T1 and T2 could be short ( $200 \mathrm{~ms} ; 67.5 \%$ of trials) or long ( $800 \mathrm{~ms} ; 32.5 \%$ of trials). At $1500 \mathrm{~ms}$ after the stream ended, participants were asked to report the two digits by typing the numbers in order using an external number pad. If they did not see one or both numbers, they were instructed to guess.

Participants first practiced the task for 15 trials. In the first 8 practice trials, stimuli were presented at half speed ( $100 \mathrm{~ms}$ duration followed by a $100 \mathrm{~ms}$ blank). They then performed either 4 or 6 blocks (depending on the condition of the patient) of 37 trials each, resulting in 100 or 150 short-interval trials and 48 or 72 long-interval trials, respectively, all intermixed within blocks.

Participants were instructed to keep their eyes at the center of the screen (at the fixation cross or at the stream of stimuli) at all times, except during the question period. Specifically, they were asked to wait with moving their eyes down to their response hand until the first question ("what was the first number?") popped up, to reduce eye movements from creating artifacts in the EEG signal during target processing. They were also asked to move their eyes back to the center of the screen while or right after entering their second answer, so that they looked at the fixation cross again at the beginning of the next trial. Responses were unspeeded.

Intracranial EEG ( $i E E G$ ) recording. While patients performed the $\mathrm{AB}$ task, we recorded iEEG from the implanted DBS electrodes using custom extension wires for the 64-channel (Advanced Neuro Technology BV) amplifier. We also recorded both the horizontal and vertical EOG, with bipolar electrodes placed at the outer canthi of both eyes and above and below the left eye, respectively. Although scalp EEG was also recorded using 64 shielded $\mathrm{Ag} / \mathrm{AgCl}$ electrodes following the international 10/10 system, we did not process these data further because of the poor signal quality due to the placement of postoperative bandages on the scalp. The EEG was recorded at $1024 \mathrm{~Hz}$, except for one patient where data were recorded at $512 \mathrm{~Hz}$.

Behavioral data analysis. To determine the presence of an AB, T2 accuracy in short and long interval trials was compared using a paired $t$ test. $\mathrm{T} 2$ accuracy was based only on those trials in which T1 was correctly reported.

iEEG data analysis. Offline preprocessing of iEEG data was performed using the EEGLAB toolbox running in MATLAB (The MathWorks). The iEEG at a given contact point was referenced to the local average activity of all contacts in that hemisphere. Visual inspection revealed that no data were recorded (flat line) at left contact point 4 for one patient, and at right contact point 2 for another patient (with contact point 1 being the most ventral one). Extreme high-frequency noise was visible at right contact point 2 for a third patient. These contact points in these patients were thus excluded from data analysis and were also not used for average referencing. Data were subsequently high-pass filtered at $0.5 \mathrm{~Hz}$ to remove slow drifts. For each condition of interest, trials were then epoched in synchrony with $\mathrm{T} 1$ onset (-2000 to $2500 \mathrm{~ms}$ ), and trials containing artifacts (drifts, etc.) or eye blinks on the vertical EOG channel during target presentation were rejected through visual inspection. This led to rejection of six trials for one subject. No trials were rejected for the other subjects. Following previous studies, we focused our analysis on oscillatory activity in the lower frequency range $(<30 \mathrm{~Hz})$, as well as on the ventral-most contact points at the core of the nucleus accumbens in each hemisphere (Cohen et al., 2012; Figee et al., 2013; Smolders et al., 2013), which appear to lie very close to where we previously observed greater conscious perception-related activity to consciously perceived compared with missed T2s with fMRI (Slagter et al., 2010).

Time-frequency analysis. To examine the role of the ventral striatum in the $A B$, our primary analysis focused on differences in target-induced oscillatory activity (or power) between T2-seen (no-blink) and T2unseen (blink) trials. Time-frequency representations of power and phase were calculated for each trial using sliding Hanning tapers with an adaptive time window of two cycles for each frequency $(1-30 \mathrm{~Hz}$ in logarithmically spaced steps). This approach has been used often in previous studies (e.g., Mazaheri et al., 2009). Time-frequency representations were computed separately for each condition (blink, no-blink), interval (short, long), contact point (left, right), and participant, and baseline corrected using the time window -500 to $-200 \mathrm{~ms}$ before T1.

Statistics. Given the relatively small number of patients, we used a nonparametric permutation procedure used in previous studies to assess statistical significance of the time-frequency data (Cohen et al., 2009). For the time-frequency data, we first randomly relabeled T2-unseen and T2-seen trials and created 1000 permuted difference maps of power. Next, at each time-frequency point, the true observed difference between T2-unseen and T2-seen trials was subtracted from the mean permuted difference and divided by the SD of the permuted differences to obtain a $z$ value. This $z$ value reflects the standardized distance away from the distribution of time-frequency power expected by chance. We chose a $z$ value corresponding to a $p$ value of 0.05 as the threshold for significance and a cluster size of 25 time-frequency pixels. In case of a significant effect, post hoc analyses were conducted to determine whether effects were driven by changes in $\mathrm{T} 2$-seen or T2-unseen trials by comparing mean activity in the significant time-frequency cluster in T2-seen (or T2-unseen) trials to mean baseline activity in a corresponding frequency range in T2-seen (or T2-unseen) trials.

\section{Results}

Patients displayed a robust $\mathrm{AB}$ : they more often failed to perceive $\mathrm{T} 2$ when it followed T1 after 200 than after $800 \mathrm{~ms}$ (Fig. $2 ; t_{(6)}=$ $4.0, p=0.007)$. Comparable with previous studies with healthy adults, T1 accuracy was high (on average, $85 \%$ ) regardless of the interval between the two targets $\left(t_{(6)}=0.04, p=0.972\right)$.

To examine the role of the ventral striatum in the $A B$, our primary analysis focused on the neural differences in targetinduced oscillatory activity (or power) between trials in which T1 and $\mathrm{T} 2$ were both consciously perceived (T2-seen trials) and trials in which $\mathrm{T} 1$ was seen, but $\mathrm{T} 2$ was missed (T2-unseen trials). In line with a contribution of the ventral striatum to the $A B$, this analysis revealed differences in both $\mathrm{T} 1$ and $\mathrm{T} 2$ processing between trials in which $\mathrm{T} 2$ was seen versus missed (Figs. 3, 4). First, the $\mathrm{AB}$ was foreshadowed by short-latency differences in $\mathrm{T} 1$ processing between T2-unseen and T2-seen trials. Specifically, the imminent failure to perceive T2 was signaled by a T1-induced transient burst of activity in the $\alpha$ and low $\beta$ range $(8-16 \mathrm{~Hz})$ occurring as early as $80 \mathrm{~ms}$ after the first target $(80-140 \mathrm{~ms})$ in the left ventral striatum (Fig. 3). Only in trials in which T2 was 
$\%$ T1 correct

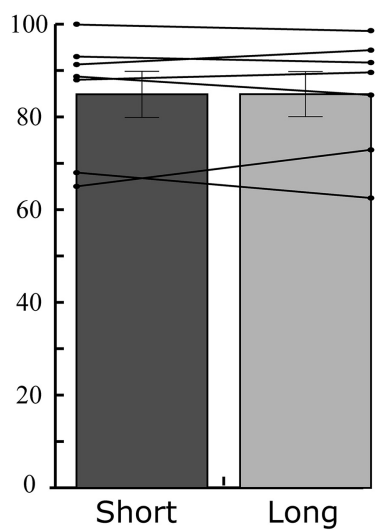

$\% \mathrm{~T} 2 / \mathrm{T} 1$ correct

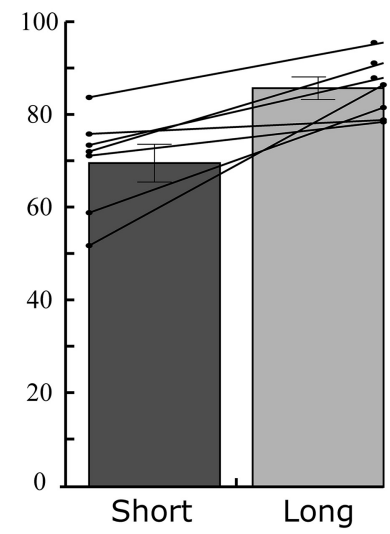

Figure 2. $A B$ task performance. Percentage $T 1$ accuracy (left) and percentage $T 2$ accurate given $\mathrm{T} 1$ correct (T2/T1) (right) are shown separately for short (200 ms) and long (800 ms) $\mathrm{T} 1-\mathrm{T} 2$ interval trials, for each patient (lines) and at the group level (bars). As shown, a robust AB was observed as reflected by lower $\mathrm{T} 2 / \mathrm{T} 1$ accuracy in short interval compared with long interval trials. Error bars indicate SEM.

missed, did T1 induce this short-latency increase in $\alpha$ low $\beta$ activity (Figs. 3B, 4). Post hoc analyses confirmed that this early response was only induced by $\mathrm{T} 1$ in $\mathrm{T} 2$-unseen trials $\left(t_{(6)}=2.75\right.$, $p=0.055)$, not in T2-seen trials $\left(t_{(6)}=0.55, p=0.59\right)$. This effect was not observed for the right ventral striatum.

Second, conscious $\mathrm{T} 2$ perception was associated with an increase in $\theta(4-8 \mathrm{~Hz})$ oscillatory activity between $\sim 150$ and $400 \mathrm{~ms}$ in both the left and right ventral striatum (Fig. 3). For the left ventral striatum, it can clearly be seen that when both targets were consciously perceived (T2-seen trials), this increase in $\theta$ activity was observed between 200 and $400 \mathrm{~ms}$ after each target onset (Fig. 4B). However, when only $\mathrm{T} 1$ was seen (T2-unseen trials), only the first increase in $\theta$ activity was present (Fig. 4A). Of further note, when T2 followed T1 after a long interval, the second increase in $\theta$ activity was correspondingly shifted in time (Fig. 4C), confirming that the second increase in $\theta$ power observed in short-interval T2-seen trials is related to (conscious) T2 processing. The difference in T2-induced $\theta$ power between T2-seen and T2-unseen trials was significant between 215 and $400 \mathrm{~ms}$ post-T2 in the left ventral striatum and between 150 and 280 $\mathrm{ms}$ in the right ventral striatum (Fig. 3). Post hoc analyses confirmed that the $\theta$ response to T2 was only significantly increased from baseline in the left ventral striatum in trials in which T2 was seen $\left(t_{(6)}=\right.$ $2.64, p=0.05)$, and not in trials in which $\mathrm{T} 2$ was not seen $\left(t_{(6)}=1.05\right.$, $p=0.33$ ) (Fig. $3 B$ ). However, in the right ventral striatum, the increase in $\theta$ activity to $\mathrm{T} 2$ was not significantly different from baseline in T2-seen trials $\left(t_{(6)}=1.87, p=0.1\right)$, indicating that the effect was less robust in the right hemisphere. Thus, only consciously perceived T2's were signaled by $\theta$ oscillatory activity in the ventral striatum. This effect was also visible at the two most dorsal contact points ( 3 and 4 ) in the left ventral ALIC (data not shown).

Last, conscious T2 perception was associated with a greater increase in $\beta$-band $(15-30 \mathrm{~Hz})$ activity in T2-seen versus T2unseen trials between 210 and $260 \mathrm{~ms}$ after T 2 in the right ventral striatum (Fig. 3). This $\beta$ increase was not significantly increased from baseline in either condition (T2-seen trials: $t_{(6)}=1.84, p=$ 0.2 ; T2-unseen trials: $t_{(6)}=0.18$. $p=0.86$; Figs. $\left.3 B, 4\right)$.

Thus, the $\mathrm{AB}$ was associated with differences in both $\mathrm{T} 1$ and $\mathrm{T} 2$ processing; $\mathrm{T} 1$ processing influenced the ability to consciously perceive T2, as indicated both by stronger $\alpha / \beta$ activity between 80 and $140 \mathrm{~ms}$ after $\mathrm{T} 1$ in the left ventral striatum. Moreover, only perceived T2's elicited a $\theta$ response between $150-280 \mathrm{~ms}$ in the right ventral striatum and $200-400 \mathrm{~ms}$ in the left ventral striatum, and a transient increase in $\beta$ activity between 210 and 260 $\mathrm{ms}$ in the right ventral striatum.

As T1 could have one of two colors (red or green), we ran a control analysis to ensure that observed differences in $\mathrm{T} 1$ processing between T2-seen and T2-unseen trials could not be accounted for by differences in the relative contribution of red $\mathrm{T} 1$ versus green T1 trials between trial types. Specifically, we ran an additional repeated-measures ANOVA with T1 color and interval (short vs long) as within-subject variables. This analysis importantly showed that T2 detection was not affected by $\mathrm{T} 1$ color (no main effect of T1 color: $F_{(1,6)}=0.012 ; p=0.915$ ), nor was $\mathrm{AB}$ size (no interaction between T1 color and Interval: $F_{(1,6)}=0.336$; $p=0.583)$, excluding this possibility.

\section{Discussion}

This study aimed to shed more light on the role of the ventral striatum in conscious perception. We found that conscious T2 perception was not only reflected in, but also influenced by, ventral striatal activity in that responses to $\mathrm{T} 1$ foreshadowed the $\mathrm{AB}$ to T2. Specifically, only in T2-unseen trials, T1 elicited a shortlatency $(80-140 \mathrm{~ms})$ increase in $\alpha$ and lower $\beta$ activity $(8-16 \mathrm{~Hz})$ in the left ventral striatum. This novel finding suggests that the $\mathrm{AB}$ to $\mathrm{T} 2$ is determined by $\mathrm{T} 1$ processing at a much earlier processing stage than commonly assumed (Dux and Marois, 2009; Martens and Wyble, 2010). Our second main finding was that only consciously perceived $\mathrm{T} 2 \mathrm{~s}$ were associated with an increase in $\theta$ activity between $215-400 \mathrm{~ms}$ and $150-280 \mathrm{~ms}$ in the left and right ventral striatum, respectively, as well as with transient $\beta$-band activity between 210 and $260 \mathrm{~ms}$ in the right ventral striatum. Thus, we also observed signals related to conscious experience in the ventral striatum before, or in the time range in which the global network of frontoparietal regions implicated in consciousness is activated (Sergent et al., 2005; Dehaene and Changeux, 2011). Together, these findings suggest that the ventral striatum may contribute to conscious perception and provide first insight into the time course of its contributions. They may also shed novel light on the mechanisms that give rise to one of the most studied phenomena in the consciousness literature: the attentional blink.

Strikingly, the $\mathrm{AB}$ was associated with differences in $\mathrm{T} 1$ processing as early as $80 \mathrm{~ms}$ after T1 (i.e., much earlier than previously shown with scalp-EEG) (Sergent et al., 2005; Slagter et al., 2007). Specifically, this work has shown that in trials in which $\mathrm{T} 2$ goes undetected, the T1-elicited $\mathrm{P} 3 \mathrm{~b}$, a brain potential with a latency of $\sim 300-400 \mathrm{~ms}$, is delayed or larger in amplitude (Sergent et al., 2005; Slagter et al., 2007). As the P3b has been linked to several, albeit related, cognitive functions, including working memory updating (Donchin, 1981), event categorization (Kok, 2001), and decision making (Twomey et al., 2015), these findings have been taken as support for major $\mathrm{AB}$ theories that propose that $\mathrm{T} 1$ encoding renders some mechanism unavailable for T2 processing until $\mathrm{T} 1$ encoding is completed and, thus, that the $\mathrm{AB}$ is related to some later-stage information processing bottleneck (Duncan et al., 1994; Chun and Potter, 1995; Bowman and Wyble, 2007; for reviews, see Dux and Marois, 2009; Martens and Wyble, 2010; Marti et al., 2015). Yet, our findings relate the AB to differences in $\mathrm{T} 1$ processing starting at $80 \mathrm{~ms}$. This could suggest that $\mathrm{T} 1$ consolidation starts much earlier, as soon as sufficient evidence has been collected. Alternatively, the AB may be affected by $\mathrm{T} 1$ processing at a much earlier processing stage. Notably, animal work has shown that the ventral striatum responds to salient stimuli within $100 \mathrm{~ms}$. This response is thought to reflect a 


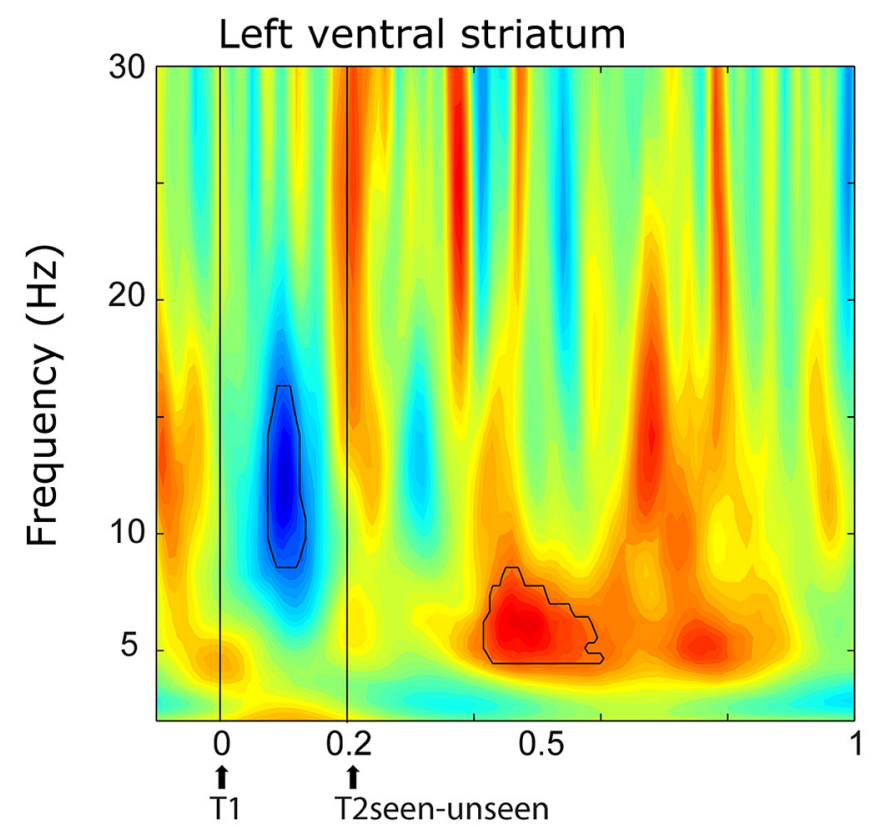

B

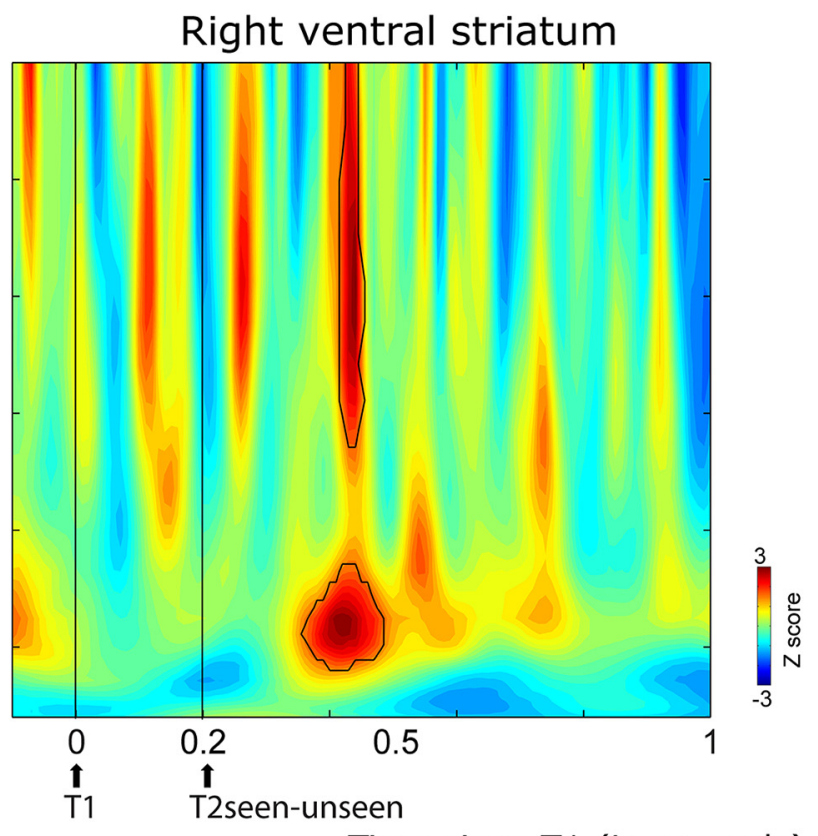

Time since T1 (in seconds)

\section{Left ventral striatum}

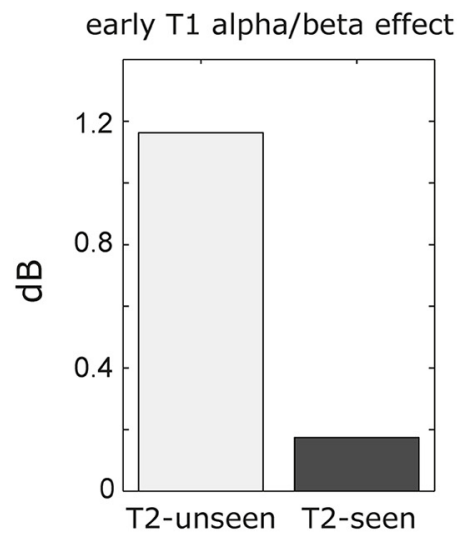

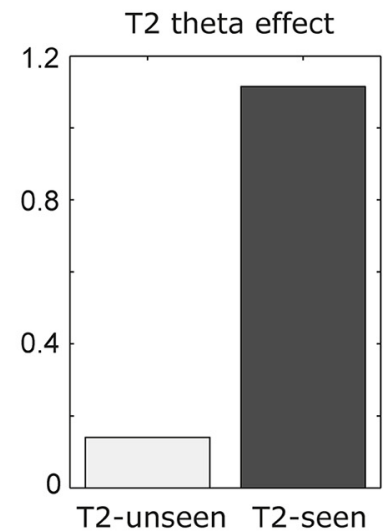
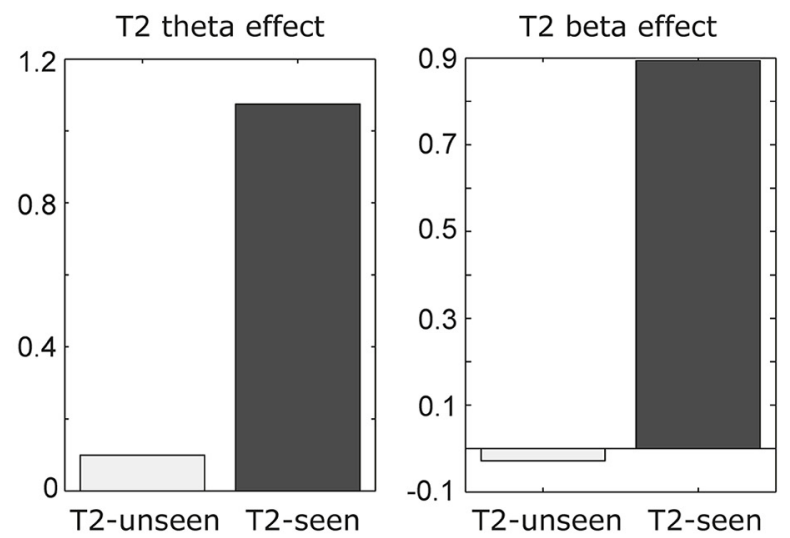

Figure 3. The $A B$ is predicted by, and reflected in, ventral striatal activity. Shown are intracranial EEG data from the left and right ventral striatum. $A$, Time-frequency representations show $z$ values reflecting the strength of differences in striatal activity between T2-seen and T2-unseen short-interval trials. Time-frequency windows where the difference reached significance are highlighted in black. Average power (in dB) within these significant windows is shown in $\boldsymbol{B}$ separately for T2-unseen and T2-seen trials. The AB was associated with an early difference in T1-induced $\alpha$ and low $\beta$ activity ( $8-16)$ between 80 and $140 \mathrm{~ms}$ after T1 in the left ventral striatum. Moreover, conscious T2 perception was associated with an increase in $\theta$ activity $(4-8 \mathrm{~Hz})$ between 215 and $400 \mathrm{~ms}$ after $\mathrm{T} 2 \mathrm{in}$ the left ventral striatum and between 150 and $280 \mathrm{~ms}$ after T2 in the right ventral striatum. Finally, in the right ventral striatum, perceived T2s elicited greater activity in the $\beta$-band (15-30 $\mathrm{Hz}$ ) activity between 210 and $260 \mathrm{~ms}$ after T2 than T2s that went undetected. Thus, the AB to T2 was foreshadowed by a short-latency response to T1 in the left ventral striatum, and conscious T2 perception was signaled by longer-latency ventral striatal activity in the $\theta$ and $\beta$ bands.

signal to frontal regions to orient attention to potentially relevant information for further processing (Redgrave et al., 1999b; Horvitz, 2000; Overton et al., 2014). Although this warrants further research, the short-latency increase in $\alpha / \beta$ activity may thus reflect an early alerting signal triggered by a salient stimulus, the strength of which determines the extent of higher-order stimulus processing, and ability of the brain to pick up on a subsequently presented target stimulus (Slagter et al., 2009). This possibility receives initial support from a study in which early evoked activity $(80-180 \mathrm{~ms})$ in the nucleus accumbens related to deviancy detection predicted the amplitude of the scalp P3b (Dürschmid et al., 2016). Yet, future studies that manipulate, for example, T1 saliency are necessary to draw firm conclusions regarding the functional significance of our early $\alpha / \beta$ effect.

Intriguingly, the short-latency difference in T1 processing was observed in the ventral striatum. This raises the question how the ventral striatum, which does not directly receive visual input, can in some trials "know" so quickly after T1, which differed from the distractors in color and shape/identity, that a salient stimulus has been presented. Animal research shows that short-latency visual in- 
A

\section{Left ventral striatum}

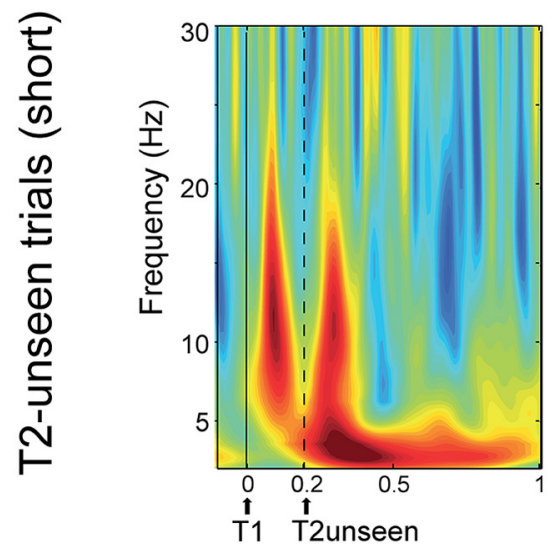

\section{Right ventral striatum}

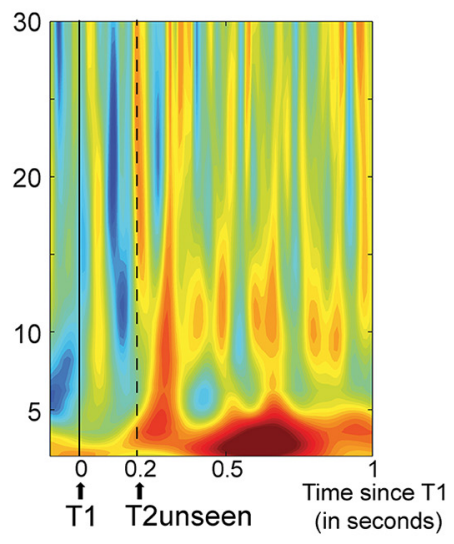

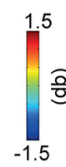
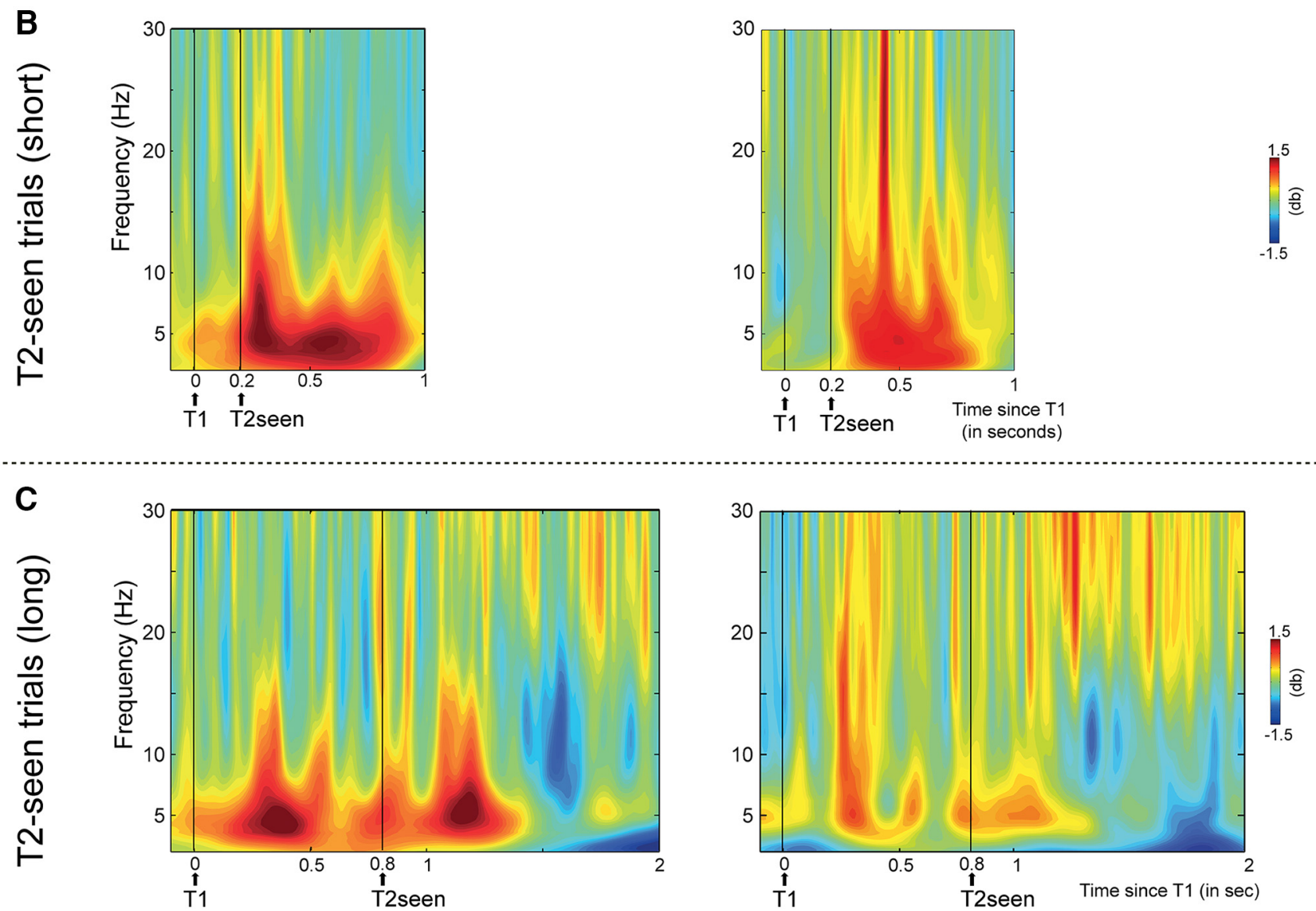

Figure 4. The failure to perceive $\mathrm{T} 2$ is foreshadowed by early $(80-140 \mathrm{~ms}) \mathrm{T} 1$ processing in the ventral striatum, and conscious $\mathrm{T} 2$ target perception is associated with later ( $200-400 \mathrm{~ms})$ ventral striatal activity. Shown are intracranial EEG data from the left (left figures) and right (right figures) ventral striatum. Time-frequency representations show oscillatory activity induced by $\mathrm{T} 1$ and $\mathrm{T} 2$ $\boldsymbol{A}$, Short-interval T2-unseen $\boldsymbol{B}$, short-interval T2-seen, and $\boldsymbol{C}$, long-interval T2-seen trials. In trials in which T2 was not seen, T1 induced a strong increase in $\alpha$ and low $\beta$ oscillatory activity (8-16) between 80 and $140 \mathrm{~ms}$ after $\mathrm{T} 1$ in the left ventral striatum. Moreover, in the left ventral striatum, when T2 was consciously perceived, an increase in $\theta$ oscillatory activity (4-8 Hz) was observed 215- $400 \mathrm{~ms}$ after each target onset. However, when only $\mathrm{T} 1$ was seen, only the first increase in $\theta$ activity was present. Moreover, the second increase in $\theta$ activity is shifted in time with the presentation of $\mathrm{T} 2$ in long-interval trials, confirming that it is related to conscious perception of T2. Thus, only consciously perceived targets were signaled by $\theta$ oscillatory activity between 200 and $400 \mathrm{~ms}$, in particular, in the left ventral striatum. Finally, conscious T2 perception was associated with a transient increase in $\beta$-band activity $(15-30 \mathrm{~Hz})$ in the right ventral striatum $210-260 \mathrm{~ms}$ after T2.

formation is provided by the superior colliculus to dopaminergic neurons, which in turn project to the striatum (Overton et al., 2014). Yet, the superior colliculus is relatively primitive and allegedly not capable of distinguishing between colors (McPeek and Keller, 2002) or complex visual stimuli (Schiller and Koerner, 1971; Goldberg and Wurtz, 1972), making it unlikely that the here observed shortlatency response reflects input from this region. At a slightly longer latency (after $\sim 150 \mathrm{~ms}$ ), the ventral striatum can receive the results 
of complex stimulus processing via a recently discovered route by which cortical areas project to dopaminergic neurons via the superior colliculus (Overton et al., 2014). Yet, the $\alpha / \beta$ effect occurred earlier. Although the ventral striatum also receives visual information via the thalamus, this is primarily from higher-order thalamic nuclei, which receive little direct sensory input. Therefore, our findings, which indicate very short-latency information processing in the ventral striatum dependent on nonspatial visual features, cannot easily be explained by existing ideas about subcortical visual processing and warrant further research. Moreover, the fact that the early $\alpha / \beta$ effect was only triggered by T1 in T2-unseen trials further suggests that it does not simply reflect sensory $\mathrm{T} 1$ processing. This observation also raises the question as to why a physically identical T1 only elicited this response in T2-unseen, but not T2-seen, trials. Several studies have shown that differences in attentional state can influence $\mathrm{T} 1$ processing and $\mathrm{AB}$ magnitude (Olivers and Nieuwenhuis, 2005; Slagter et al., 2007; van Vugt and Slagter, 2014), raising the possibility that trial-to-trial fluctuations in attentional state may have contributed to observed effects. Notably, $\alpha$ and $\beta$ oscillations have been specifically related to top-down, feedback-related processing (Bastos et al., 2015). Thus, although speculative, the extent to which T1 captured attention or placed demands on consolidation processes may have depended on pretarget attentional state. Alternatively, differences in bottom-up T1 strength across trials, caused by variability across trials in the specific target-distracter sequence and hence distractor masking, may have also influenced $\mathrm{T} 1$ processing (Bowman and Wyble, 2007). Future studies that manipulate attentional state and $\mathrm{T} 1 \mathrm{saliency}$ are necessary to determine the functional significance of our early $\alpha / \beta$ effect. Nevertheless, our findings indicate that the $\mathrm{AB}$ is related to $\mathrm{T} 1$ processing at a much earlier processing stage than is commonly assumed, at the subcortical level. They may also extend recent findings that indicate that, although visual consciousness and endogenous (top-down) attention may be neurally dissociated (Koch and Tsuchiya, 2007; Wyart and TallonBaudry, 2008), exogenous spatial attention (Chica and Bartolomeo, 2012) and phasic alertness (Kusnir et al., 2011) are important antecedents of conscious experience and facilitate conscious access by calling upon frontoparietal networks to orient attention.

Importantly, striatal responses to T1 not only prevented conscious access to T2, conscious T2 perception was also signaled by striatal activity in the $\theta$ band. This is notable as most theories of consciousness focus exclusively on the cortex and/or thalamocortical interactions (Rees et al., 2002; Haynes, 2009; Dehaene and Changeux, 2011; Lau and Rosenthal, 2011; Aru et al., 2012; van Gaal and Lamme, 2012), and are agnostic on striatal contributions. $\theta$ oscillations are associated with the active intake of sensory stimuli (Bastos et al., 2015), but are also observed in structures further down the processing stream, including the hippocampus (Colgin, 2013). Hippocampal-generated $\theta$ oscillations are key in setting the dynamics for memory encoding and retrieval within cortical circuits (Hasselmo and Stern, 2014). As the ventral striatum allegedly does not generate $\theta$ oscillations itself (van der Meer and Redish, 2011) and intracranial EEG measures local field potentials (i.e., neuronal input), the observed $\mathrm{T} 2$ detection-related $\theta$ response may thus reflect hippocampal-dependent processes. The nucleus accumbens, which also receives inputs from the amygdala, prefrontal cortex, and the ventral tegmental area, projects to both the mediodorsal nucleus of the thalamus and the thalamic nucleus reticularis, which in turn project to the prefrontal cortex. The nucleus accumbens is thus well positioned to integrate information from different sources and select which information is broadcasted through the brain (via the thalamic nucleus reticularis) (Scheibel, 1980) or selected for sustained cortical representation (via the mediodorsal nucleus of the thala- mus) (Goto and Grace, 2008). This is significant as several influential theories propose that consciousness is related to the "broadcasting" of sensory information to the whole brain and that thalamocortical circuits serve as an important mediator of such broadcasting (Newman and Baars, 1993; Crick, 1995; Tononi and Edelman, 1998; Baars, 2005; Dehaene and Changeux, 2005, 2011). Future studies are necessary to determine how the striatum may precisely influence thalamocortical interactions and conscious perception.

As for the T2 perception-related increase in $\beta$ activity, a recent iEEG study reported reduced $\beta$-band activity in the ventral striatum at a similar latency to rare versus frequent scene images (Zaehle et al., 2013), suggesting that $\beta$-band activity may signal contextual deviancy. Yet, we observed an increase in $\beta$ activity to perceived T2s. This discrepancy in findings might relate to differences in the specific task or reference procedure used.

Our results extend findings from neuroimaging studies (Christensen et al., 2006; Slagter et al., 2010, 2012; Van Opstal et al., 2014; Bisenius et al., 2015; Chica et al., 2016) by revealing the time course of conscious perception-related striatal activity. Importantly, some of these studies used simple backward masking tasks with only one stimulus (Christensen et al., 2006; Van Opstal et al., 2014; Bisenius et al., 2015), in which conscious access is not dependent on attentional selection (Dehaene and Changeux, 2011) as in the AB task. Yet, many fMRI studies did not report conscious-related activity in the striatum. Possibly, fMRI does not provide a sensitive measure of consciousness-related activity in the basal ganglia due to the nature of the BOLD response; BOLD activity mostly reflects local field potential activity between 20 and $60 \mathrm{~Hz}$ (Goense and Logothetis, 2008) and correlates negatively with $\alpha$ power (Laufs et al., 2003; Scheeringa et al., 2011). Low-frequency oscillatory activity, as observed here, may hence not be reflected in increased BOLD activity or even result in decreased BOLD activity. Combined with the fact that basal ganglia activity cannot be measured with scalp-EEG (Cohen et al., 2011), this might explain the exclusion of a striatal contribution in many theories of consciousness. Yet, the striatum is well positioned to gate cortical information flow and integrate the massively parallel and distributed information capacity of the cerebral cortex into the limited-capacity, sequential mode of operation required to form a coherent percept of our environment. Albeit speculative, our observations may provide initial support for this idea.

A role for striatum-dependent gating mechanisms in the $A B$ fits with influential theories that attribute the $\mathrm{AB}$ to dysfunctional gating of information (Di Lollo et al., 2005; Bowman and Wyble, 2007; Olivers and Meeter, 2008). For example, in the episodic simultaneous type serial token model (Bowman and Wyble, 2007), target perception critically relies on the capacity to rapidly detect that a stimulus is salient when a fleeting representation of it arises among (temporally) competing stimuli, and the ability to sustain this representation through transient attentional enhancement for memory encoding. In this model, ongoing consolidation of T1 has an inhibitory effect on T2 attentional selection, resulting in impaired T2 detection. According to another influential theory (Olivers and Meeter, 2008), the AB reflects the workings of a rapidly responding gating system. Specifically, T1 elicits transient excitatory feedback activity within $100 \mathrm{~ms}$ meant to provide access to working memory. However, accidentally, the subsequent post-T1 distracter is "boosted," resulting in a strong inhibitory feedback response, which closes the gate to working memory for T2. This theory actually postulated a possible role for the basal ganglia in the AB.

Although behaviorally our mixed-patient data are very similar to typical findings in healthy adults, the question remains how 
our findings translate to the healthy human brain. Answering this question requires the development of methods that can noninvasively measure subcortical activity with high temporal precision in healthy humans.

In conclusion, our results shed new light on the mechanisms that give rise to the $A B$, by revealing that the $A B$ may be due to very early T1-driven attentional capture. More generally, by showing that conscious perception is modulated by ventral striatal activity, they suggest that the neural mechanisms underlying conscious access may not be confined to the thalamocortical complex alone.

\section{References}

Aru J, Bachmann T, Singer W, Melloni L (2012) Distilling the neural correlates of consciousness. Neurosci Biobehav Rev 36:737-746. CrossRef Medline

Baars BJ (1993) A cognitive theory of consciousness. Cambridge: Cambridge UP.

Baars BJ (2005) Global workspace theory of consciousness: toward a cognitive neuroscience of human experience. Prog Brain Res 150:45-53. CrossRef Medline

Bastos AM, Vezoli J, Bosman CA, Schoffelen JM, Oostenveld R, Dowdall JR, De Weerd P, Kennedy H, Fries P (2015) Visual areas exert feedforward and feedback influences through distinct frequency channels. Neuron 85:390-401. CrossRef Medline

Bisenius S, Trapp S, Neumann J, Schroeter ML (2015) Identifying neural correlates of visual consciousness with ALE meta-analyses. Neuroimage 122:177-187. CrossRef Medline

Bowman H, Wyble B (2007) The simultaneous type, serial token model of temporal attention and working memory. Psychol Rev 114:38-70. CrossRef Medline

Chica AB, Bartolomeo P (2012) Attentional routes to conscious perception. Front Psychol 3:1. CrossRef Medline

Chica AB, Bayle DJ, Botta F, Bartolomeo P, Paz-Alonso PM (2016) Interactions between phasic alerting and consciousness in the fronto-striatal network. Sci Rep 6:31868. CrossRef Medline

Christensen MS, Ramsøy TZ, Lund TE, Madsen KH, Rowe JB (2006) An fMRI study of the neural correlates of graded visual perception. Neuroimage 31:1711-1725. CrossRef Medline

Chun MM, Potter MC (1995) A two-stage model for multiple target detection in rapid serial visual presentation. J Exp Psychol Hum Percept Perform 21:109-127. CrossRef Medline

Cohen MX, Axmacher N, Lenartz D, Elger CE, Sturm V, Schlaepfer TE (2009) Good vibrations: cross-frequency coupling in the human nucleus accumbens during reward processing. J Cogn Neurosci 21:875-889. CrossRef Medline

Cohen MX, Cavanagh JF, Slagter HA (2011) Event-related potential activity in the basal ganglia differentiates rewards from nonrewards: temporospatial principal components analysis and source localization of the feedback negativity: commentary. Hum Brain Mapp 32:2270-2271. CrossRef Medline

Cohen MX, Bour L, Mantione M, Figee M, Vink M, Tijssen MA, van Rootselaar AF, van den Munckhof P, Schuurman PR, Denys D (2012) Top-down-directed synchrony from medial frontal cortex to nucleus accumbens during reward anticipation. Hum Brain Mapp 33:246-252. CrossRef Medline

Colgin LL (2013) Mechanisms and functions of theta rhythms. Annu Rev Neurosci 36:295-312. CrossRef Medline

Crick F (1995) Astonishing hypothesis: the scientific search for the soul. New York: Simon \& Schuster.

Dehaene S, Changeux JP (2005) Ongoing spontaneous activity controls access to consciousness: a neuronal model for inattentional blindness. PLoS Biol 3:e141. CrossRef Medline

Dehaene S, Changeux JP (2011) Experimental and theoretical approaches to conscious processing. Neuron 70:200-227. CrossRef Medline

Dehaene S, Naccache L (2001) Towards a cognitive neuroscience of consciousness: basic evidence and a workspace framework. Cognition 79: 1-37. CrossRef Medline

Denys D, Mantione M, Figee M, van den Munckhof P, Koerselman F, Westenberg H, Bosch A, Schuurman R (2010) Deep brain stimulation of the nucleus accumbens for treatment-refractory obsessive-compulsive disorder. Arch Gen Psychiatry 67:1061-1068. CrossRef Medline

Di Lollo V, Kawahara J, Shahab Ghorashi SM, Enns JT (2005) The atten- tional blink: resource depletion or temporary loss of control? Psychol Res 69:191-200. CrossRef Medline

Donchin E (1981) Presidential address, 1980. Surprise! Surprise? Psychophysiology 18:493-513. CrossRef Medline

Duncan J, Ward R, Shapiro K (1994) Direct measurement of attentional dwell time in human vision. Nature 369:313-315. CrossRef Medline

Dürschmid S, Zaehle T, Hinrichs H, Heinze HJ, Voges J, Garrido MI, Dolan RJ, Knight RT (2016) Sensory deviancy detection measured directly within the human nucleus accumbens. Cereb Cortex 26:1168-1175. CrossRef Medline

Dux PE, Marois R (2009) The attentional blink: a review of data and theory. Atten Percept Psychophys 71:1683-1700. CrossRef Medline

Figee M, Luigjes J, Smolders R, Valencia-Alfonso CE, van Wingen G, de Kwaasteniet B, Mantione M, Ooms P, de Koning P, Vulink N, Levar N, Droge L, van den Munckhof P, Schuurman PR, Nederveen A, van den Brink W, Mazaheri A, Vink M, Denys D (2013) Deep brain stimulation restores frontostriatal network activity in obsessive-compulsive disorder. Nat Neurosci 16:386-387. CrossRef Medline

Goense JB, Logothetis NK (2008) Neurophysiology of the BOLD fMRI signal in awake monkeys. Curr Biol 18:631-640. CrossRef Medline

Goldberg ME, Wurtz RH (1972) Activity of superior colliculus in behaving monkey: I. Visual receptive fields of single neurons. J Neurophysiol 35: 542-559. Medline

Goto Y, Grace AA (2008) Limbic and cortical information processing in the nucleus accumbens. Trends Neurosci 31:552-558. CrossRef Medline

Hasselmo ME, Stern CE (2014) Theta rhythm and the encoding and retrieval of space and time. Neuroimage 85:656-666. CrossRef Medline

Haynes JD (2009) Decoding visual consciousness from human brain signals. Trends Cogn Sci (Regul Ed) 13:194-202. CrossRef Medline

Horvitz JC (2000) Mesolimbocortical and nigrostriatal dopamine responses to salient non-reward events. Neuroscience 96:651-656. CrossRef Medline

Koch C, Tsuchiya N (2007) Attention and consciousness: two distinct brain processes. Trends Cogn Sci (Regul Ed) 11:16-22. CrossRef Medline

Kok A (2001) On the utility of P3 amplitude as a measure of processing capacity. Psychophysiology 38:557-577. CrossRef Medline

Kusnir F, Chica AB, Mitsumasu MA, Bartolomeo P (2011) Phasic auditory alerting improves visual conscious perception. Conscious Cogn 20:12011210. CrossRef Medline

Lau H, Rosenthal D (2011) Empirical support for higher-order theories of conscious awareness. Trends Cogn Sci (Regul Ed) 15:365-373. CrossRef Medline

Laufs H, Kleinschmidt A, Beyerle A, Eger E, Salek-Haddadi A, Preibisch C, Krakow K (2003) EEG-correlated fMRI of human alpha activity. Neuroimage 19:1463-1476. CrossRef Medline

MacDonald AA, Naci L, MacDonald PA, Owen AM (2015) Anesthesia and neuroimaging: investigating the neural correlates of unconsciousness. Trends Cogn Sci (Regul Ed) 19:100-107. CrossRef Medline

Martens S, Wyble B (2010) The attentional blink: past, present, and future of a blind spot in perceptual awareness. Neurosci Biobehav Rev 34:947957. CrossRef Medline

Marti S, King JR, Dehaene S (2015) Time-resolved decoding of two processing chains during dual-task interference. Neuron 88:1297-1307. CrossRef Medline

Mazaheri A, Nieuwenhuis IL, van Dijk H, Jensen O (2009) Prestimulus alpha and mu activity predicts failure to inhibit motor responses. Hum Brain Mapp 30:1791-1800. CrossRef Medline

McPeek RM, Keller EL (2002) Saccade target selection in the superior colliculus during a visual search task. J Neurophysiol 88:2019-2034. Medline

Newman J, Baars BJ (1993) A neural attentional model for access to consciousness: a global workspace perspective. Concepts Neurosci 4:255290.

Newman J, Grace AA (1999) Binding across time: the selective gating of frontal and hippocampal systems modulating working memory and attentional states. Conscious Cogn 8:196-212. CrossRef Medline

Olivers CN, Meeter M (2008) A boost and bounce theory of temporal attention. Psychol Rev 115:836-863. CrossRef Medline

Olivers CN, Nieuwenhuis S (2005) The beneficial effect of concurrent taskirrelevant mental activity on temporal attention. Psychol Sci 16:265-269. CrossRef Medline

Overton PG, Vautrelle N, Redgrave P (2014) Sensory regulation of dopaminergic cell activity: phenomenology, circuitry and function. Neuroscience 282C:1-12. CrossRef Medline

Raymond JE, Shapiro KL, Arnell KM (1992) Temporary suppression of vi- 
sual processing in an RSVP task: an attentional blink? J Exp Psychol Hum Percept Perform 18:849-860. CrossRef Medline

Redgrave P, Gurney K (2006) The short-latency dopamine signal: a role in discovering novel actions? Nat Rev Neurosci 7:967-975. CrossRef Medline

Redgrave P, Prescott TJ, Gurney K (1999a) The basal ganglia: a vertebrate solution to the selection problem? Neuroscience 89:1009-1023. CrossRef Medline

Redgrave P, Prescott TJ, Gurney K (1999b) Is the short-latency dopamine response too short to signal reward error? Trends Neurosci 22:146-151. CrossRef Medline

Rees G, Kreiman G, Koch C (2002) Neural correlates of consciousness in humans. Nat Rev Neurosci 3:261-270. CrossRef Medline

Scheeringa R, Fries P, Petersson KM, Oostenveld R, Grothe I, Norris DG, Hagoort P, Bastiaansen MC (2011) Neuronal dynamics underlying high- and low-frequency EEG oscillations contribute independently to the human BOLD signal. Neuron 69:572-583. CrossRef Medline

Scheibel AB (1980) Anatomical and physiological substrates of arousal: a view from the bridge. New York: Raven.

Schiller PH, Koerner F (1971) Discharge characteristics of single units in superior colliculus of the alert rhesus monkey. J Neurophysiol 34:920936. Medline

Sergent C, Baillet S, Dehaene S (2005) Timing of the brain events underlying access to consciousness during the attentional blink. Nat Neurosci 8:1391-1400. CrossRef Medline

Slagter HA, Lutz A, Greischar LL, Francis AD, Nieuwenhuis S, Davis JM, Davidson RJ (2007) Mental training affects distribution of limited brain resources. PLoS Biol 5:e138. CrossRef Medline

Slagter HA, Lutz A, Greischar LL, Nieuwenhuis S, Davidson RJ (2009) Theta phase synchrony and conscious target perception: impact of intensive mental training. J Cogn Neurosci 21:1536-1549. CrossRef Medline

Slagter HA, Johnstone T, Beets IA, Davidson RJ (2010) Neural competition for conscious representation across time: an fMRI study. PLoS One 5:e10556. CrossRef Medline

Slagter HA, Tomer R, Christian BT, Fox AS, Colzato LS, King CR, Murali D, Davidson RJ (2012) PET evidence for a role for striatal dopamine in the attentional blink: functional implications. J Cogn Neurosci 24:19321940. CrossRef Medline

Smolders R, Mazaheri A, van Wingen G, Figee M, de Koning PP, Denys D
(2013) Deep brain stimulation targeted at the nucleus accumbens decreases the potential for pathologic network communication. Biol Psychiatry 74:e27-e28. CrossRef Medline

Tononi G, Edelman GM (1998) Consciousness and complexity. Science 282:1846-1851. CrossRef Medline

Twomey DM, Murphy PR, Kelly SP, O’Connell RG (2015) The classic P300 encodes a build-to-threshold decision variable. Eur J Neurosci 42:16361643. CrossRef Medline

van den Munckhof P, Bosch DA, Mantione MH, Figee M, Denys DA, Schuurman PR (2013) Active stimulation site of nucleus accumbens deep brain stimulation in obsessive-compulsive disorder is localized in the ventral internal capsule. Acta Neurochir Suppl 117:53-59. CrossRef Medline

van der Meer MA, Redish AD (2011) Theta phase precession in rat ventral striatum links place and reward information. J Neurosci 31:2843-2854. CrossRef Medline

van Gaal S, Lamme VA (2012) Unconscious high-level information processing: implication for neurobiological theories of consciousness. Neuroscientist 18:287-301. CrossRef Medline

Van Opstal F, Van Laeken N, Verguts T, van Dijck JP, De Vos F, Goethals I, Fias W (2014) Correlation between individual differences in striatal dopamine and in visual consciousness. Curr Biol 24:R265-R266. CrossRef Medline

van Schouwenburg MR, den Ouden HE, Cools R (2015) Selective attentional enhancement and inhibition of fronto-posterior connectivity by the basal ganglia during attention switching. Cereb Cortex 25:1527-1534. CrossRef Medline

van Vugt MK, Slagter HA (2014) Control over experience? Magnitude of the attentional blink depends on meditative state. Conscious Cogn 23:32-39. CrossRef Medline

Vijayan S, Kopell NJ (2012) Thalamic model of awake alpha oscillations and implications for stimulus processing. Proc Natl Acad Sci U S A 109:18553-18558. CrossRef Medline

Wyart V, Tallon-Baudry C (2008) Neural dissociation between visual awareness and spatial attention. J Neurosci 28:2667-2679. CrossRef Medline

Zaehle T, Bauch EM, Hinrichs H, Schmitt FC, Voges J, Heinze HJ, Bunzeck N (2013) Nucleus accumbens activity dissociates different forms of salience: evidence from human intracranial recordings. J Neurosci 33: 8764-8771. CrossRef Medline 